\title{
Troca de saberes e fazeres indígenas e quilombolas no Colégio de Aplicação João XXIII: educação para a democracia por meio da interculturalidade crítica da Educação Física escolar ${ }^{1}$
}

\begin{abstract}
Resumo:
Ao dialogar com os formandos do Ensino Médio do Colégio de Aplicação João XXIII sobre a resistência a determinados temas, surgiu o desejo de analisar como se elencavam os conteúdos na Educação Física nesta escola. Este trabalho pretende divulgar os processos de desenvolvimento de aulas sobre danças tradicionais, embasadas no direito ao conhecimento da diversidade cultural brasileira, que culminou na organização do evento "Troca de saberes e fazeres indígenas e quilombolas". Por meio de um estudo etnográfico com noventa formandos e dois professores, analisou-se o diário de campo de cinco estagiários pela linha interpretativa da Antropologia Social. Concluiu-se que, a partir da interculturalidade crítica, professores e alunos foram motivados a repensar todo o funcionamento do ensino voltado para princípios democráticos, e, com isso, realizar um evento para todas as comunidades envolvidas.
\end{abstract}

\section{Palavras-chave:}

Troca de saberes e fazeres. Indígenas. Quilombolas. Interculturalidade crítica. Educação Física escolar.

\begin{abstract}
:
By interacting with the high school students from Colégio de Aplicação João XXIII about their resistance about certain topics, the interest to analyse how these topics are presented in Physical Education at this school emerged. This work aims to divulgate the processes regarding the developing of
\end{abstract}

\footnotetext{
1. O presente artigo faz parte das reflexões do grupo de estudo e pesquisa "Prática pedagógica em Educação Física", que funciona na Faculdade de Educação da Universidade Federal de Juiz de Fora, bem como da tese Modos de ser quilombola, indígena e português: do cruzamento de pertencimentos corpóreos nas danças tradicionais às dádivas que consolidam as identidades da Colônia do Paiol, Aldeia Araponga e Comunidade de Areosa, apresentada à banca de promoção a titular na Universidade Federal de Juiz de Fora, em 2019.

* Doutora em Educação Física; professora titular do Colégio de Aplicação João XXIII da Universidade Federal de Juiz de Fora (UFJF). E-mail: catia.duarte@ufjf.edu.br. ORCID iD: http://orcid.org/0000-0001-9247-2571.

** Bolsista do projeto de extensão "Oficinas de danças tradicionais na escola: formação de professores para discussão da diversidade e identidade sociocultural brasileira”; graduanda do curso de Serviço Social. E-mail: lauramelosoares08@gmail. com. ORCID iD: http://orcid.org/0000-0002-1067-3861.

*** Mestranda em Educação Física na Azusa Pacific University; graduada em Educação Física pela UFJF. E-mail: nyrecell@hotmail. com. ORCID iD: http://orcid.org/0000-0001-8115-7090.
} 
traditional dance classes, based on the right to know about the Brazilian cultural diversity, which led to the organization of the event "Troca de saberes e fazeres indígenas e quilombolas". Considering an ethnographic study with ninety graduating students and two teachers, analysed the field reports of five undergraduates, by the interpretative line of Social Anthropology. It has been concluded that, by critical interculturality, students and teachers were motivated to reformulate all the teaching process focused on democratic values, and, as so, to perform an event for all communities involved.

\section{Keywords:}

Exchange of knowledge and actions. Indigenous people. Quilombolas. Critical interculturality. School Physical Education.

\section{Introdução}

Desde 2005, o Colégio de Aplicação João XXIII de Juiz de Fora (CAp/JF) desenvolve Projetos Coletivos de Trabalho (PCT) nos diferentes segmentos. Um dos mais antigos é o dos terceiros anos do Ensino Médio (EM) que vem aproximando professores de diferentes áreas para abordar temas que cruzam o cotidiano dos conteúdos curriculares, como, por exemplo, a identidade brasileira na região sudeste.

Pela proximidade da cidade com o estado do Rio de Janeiro, professores visitam a região de Paraty (RJ) ao término de tais discussões. Nessa região, há três usinas nucleares, Angra 1, Angra 2 e Angra 3, estando apenas duas em atividade e sendo ambas responsáveis por 3\% de energia consumida no país (ROSSI, 2019). Considerada patrimônio nacional desde 1965, a cidade é marcada pela sua herança histórica e colonial, além da sua porção extensa do oceano Atlântico, possuindo 65 ilhas, 300 praias e uma fauna diversa proporcionada pela Mata Atlântica. A arquitetura local é composta por casas térreas, sobrados e fachadas geométricas influenciadas pela maçonaria. Além disso, a cidade histórica possui duas reservas indígenas Guarani-Mbya, ambas demarcadas pela Fundação Nacional do Índio (FUNAI), um quilombo e uma comunidade caiçara. Nelas se encontram grande acervo cultural do local: uma diversidade de músicas, artesanatos, narrativas sobre a sua realidade, culinária e festas.

A partir dessa riqueza cultural, os professores exemplificavam seus conteúdos com facilidade, no entanto, nas aulas de Educação Física (EF), devido aos alunos não terem muitas reflexões sobre danças tradicionais brasileiras em anos anteriores do currículo ou entenderem que território identitário é um discurso para outras disciplinas que não seja a Educação Física ou Artes, a aprendizagem dos saberes de origem indígena ou quilombola ficavam comprometidas. Muitos pais não aprovavam a ideia de que seus filhos dançassem segundo religiosidades distantes da realidade urbana local e começaram a enviar bilhetes pedindo que o conteúdo fosse reavaliado.

Embora se explicasse que as Leis no 9.394 (BRASIL, 1996), 10.639 (BRASIL, 2003) e 11.645 (BRASIL, 2008) eram fundamentais para acessar o patrimônio cultural do povo brasileiro, que os Decretos $\mathrm{n}^{\circ} 5.051$ (BRASIL, 2004) e 6.040 (BRASIL, 2007) e a Resolução no 8 (BRASIL, 2012) deveriam ser defendidos por todos e que a PEC 241 (CÂMARA DOS DEPUTADOS, 2016) destruiria as organizações dos diferentes grupos sociais, o retorno era que aula de $\mathrm{EF}$ deveria se ater às técnicas corporais de alguns esportes e lutas. A partir dessa convicção, ponderava-se que a origem das práticas corporais na EF e nas Artes, de forma que se tornassem culturais e sociais, quando amplamente reconhecida por muitos grupos. Fato é que, dependendo da história do lugar e das pessoas, muitas práticas não se tornam culturais, passando a ser sociais quando há interesses globais que fogem dos interesses das culturas que as compõem.

Com o tempo, notou-se a necessidade de discutir os conteúdos curriculares dentro do Departamento de EF e, com apoio dos estagiários, a ideia dos temas interdisciplinares começou a fazer sentido para os 
formandos do EM. Quando os alunos começaram a reconhecer que havia uma grande diversidade ${ }^{2}$ cultural na própria região, que os professores não tinham o hábito de ouvir a comunidade escolar para elencar os conteúdos e que, a partir das últimas eleições, os povos originários e remanescentes da região do seu PCT perdiam direitos a cada mês, entenderam que seria fundamental exercer uma cidadania para que, por meio da interculturalidade crítica $^{3}$, reelaborassem as aulas de dança, ampliassem os conceitos sobre política de identidade ${ }^{4}$ e de diferença ${ }^{5}$ no currículo da Educação Física escolar, e propusessem que os indígenas e quilombolas viessem ao colégio para dialogar sobre seus saberes e fazeres com seus professores, bem como com professores de outras escolas públicas da cidade.

Com intuito de educar para a democracia ${ }^{6}$, surgiu a ideia de trazer os visitantes para um evento com mesas que permitissem que tanto especialistas da Universidade Federal de Juiz de Fora (UFJF), quanto lideranças indígenas e quilombolas falassem sobre território e territorialidade, cuidados com o meio ambiente e currículo escolar. Importante frisar que as lideranças receberam cachês com apoio de emenda parlamentar pelas apresentações realizadas no evento, bem como alimentos e roupas de campanha realizada pelos formandos e propostas de visitas que, quando pernoitam, pagam uma taxa e colaboram com o patrimônio material e imaterial das comunidades de Paraty (RJ).

Assim, além de ouvir as insatisfações dos alunos para abordar determinados conteúdos étnicos ${ }^{7}$ de forma mais crítica, bem como ampliar o acesso à solução desse problema com outros professores da rede municipal e estadual por meio de evento acadêmico, este trabalho objetiva levar os alunos a conhecer o patrimônio material e imaterial da região sudeste durante as aulas de dança tradicional; propor espaço de discussão sobre diversidade cultural entre professores, alunos do CAp e da UFJF, professores e alunos de outras escolas públicas, povos originários e remanescentes de quilombos em um evento escolar; e exercitar a cidadania, de modo a manter o diálogo entre a universidade e as comunidades indígenas e quilombolas, verificando o que pode ser feito para ajudá-los quando o Estado não os protege.

\section{Procedimentos metodológicos}

Neste estudo etnográfico (GEERTZ, 1989) realizado em 2019, com noventa formandos do CAp e dois professores de Educação Física que participam do PCT “Pés na estrada” (Paraty - RJ), utilizou-se diário de campo de cinco estagiários de Educação Física, segundo procedimentos (FONSECA, 1999) da Antropologia Social (MAUSS, 2003; MARTINS, 2005).

Pesquisas etnográficas em escolas públicas precisam ter cuidado com a descrição densa do cotidiano, pois é preciso estranhar o familiar (compreender os motivos dos alunos em não querer dançar tradicionalmente) e familiarizar-se com o estranho (compreender as danças tradicionais in loco para desenvolver as discussões na escola), em busca de um projeto que melhore as relações humanas e, consequentemente, as relações com o conhecimento.

\footnotetext{
2. Segundo Pessoa (2017), a diversidade nasce com o fim dos nacionalismos e o surgimento da mundialização. Na virada do século XX para o XXI, assistiu-se a uma culturalização generalizada da existência, em que a construção de identidades emergiu de forma tão pulverizada que seus próprios criadores foram os interessados a lucrar com tal conceituação.

3. Para Candau (2012), essa perspectiva permite que se desconstruam preconceitos em relação aos sujeitos, articulem-se os saberes para compreender como as pessoas vivem, resgatem-se conhecimentos para criar soluções de problemas sociais, e promovam-se espaços para o diálogo e a aprendizagem, a partir de reflexões sobre práticas corporais que seguem a Lei no 10.639 (BRASIL, 2003 ). 4. A identidade é híbrida e tem ligação temporária entre os discursos e as práticas, por um lado, e processos de subjetivação que nos constroem enquanto sujeitos, de outro (HALL, 1998).

5. A diferença é uma construção histórica e social (SILVA, 2000) que, por meio de discussão de etnia, diversidade, dentre outras nas práticas socioeducativas (CANDAU, 2012), busca consenso e, ao mesmo tempo, reconhecimento e aceitação do dissenso.

6. Segundo Benevides (1990), o poder do povo ou democracia acontece quando há formação intelectual - conhecer para melhor escolher -, formação moral - consciência ética para lidar com sentimentos e razões - e formação de comportamento - tolerância frente o diferente ou o divergente para manter o bem comum.

7. Segundo Arruti (1997), o conceito de etnicidade se configura como uma atitude positiva e propositiva através da qual seriam produzidas demandas e um projeto político comum, cuja vinculação e razão de ser está no futuro.
} 
Os noventa alunos de Ensino Médio do período regular assistem a sete tempos de aula todos os dias; têm, em média, 17 anos; praticamente, $5 \%$ deles trabalham no contraturno; vivem nos bairros próximos ao centro de Juiz de Fora. Os professores vivem no centro, em bairros próximos à escola ou em sítios pouco afastados do centro de Juiz de Fora; têm, em média, 38 anos e costumam participar de grupos de estudos, orientação de estagiários, organização de eventos com professores do município e do estado.

Primeiramente, se fez um levantamento dos problemas e soluções que os alunos apresentaram, por meio dos representantes em conselho de classe ${ }^{8}$. Nas aulas de EF uma proposta de trabalho foi discutida e aceita com pontos sugeridos pelos alunos, como: pesquisas com pessoas mais velhas da comunidade escolar e reestruturação das atividades diárias que visassem à participação dos alunos na organização, execução e avaliação do processo (estranhamento dos acontecimentos no campo). De posse de alguns relatórios das aulas, definiram-se os tópicos que poderiam ser discutidos com indígenas e quilombolas, assumindo que se descreveriam as relações dos sujeitos durante o evento e a organização política dentro da instituição (CAp) (esquematização das regularidades/irregularidades). Após um tempo de trabalho, realizou-se o evento, sendo avaliado o processo de construção da proposta (desconstrução dos estereótipos), bem como sendo descritas e interpretadas as novas posturas dos envolvidos (comparação com exemplos antropológicos). A última etapa, produção de material didático a ser usado em escolas públicas (sistematização do material em modelos alternativos), encontra-se em andamento e será concluída em parceria com professores de escolas públicas e alunos do CAp (FONSECA, 1999).

Para analisar os registros no diário de campo, seguiu-se a linha interpretativa da Antropologia Social de Mauss (2003), sobre o que foi observado antes, durante e depois do evento (exemplos de potlatch), já que as interações dos sujeitos no CAp têm pressupostos antropológicos e sociológicos diferentes de outros sujeitos de outras escolas nos mais diferentes espaços. Não se valorizou somente a natureza da sociedade local, mas as condutas individuais que se tornaram elementos de um sistema simbólico coletivo que decidiu reavaliar as formas de escolha de seus conteúdos, em como seus objetivos, metodologias e avaliações. O movimento circular de dádivas/reciprocidades de caráter interpessoal (MAUSS, 2003), acionado pela força do espírito que acompanha coisas concretas (exemplo de hau) ou coisas simbólicas (exemplo de mana) durante a culminância do projeto de ensino, evidencia que a distribuição dos lugares dos membros deu-se por reconhecimento, inclusão e prestígio (MARTINS, 2005).

Por fim, por meio dos atos de dar, receber e retribuir presentes na teoria da dádiva (MAUSS, 2017), detectou-se valores democráticos (amor pela igualdade de oportunidade, respeito pela decisão coletiva, aceitação do direito de todos se manifestarem) que transformaram as aulas de danças de EF; permitiram a consolidação de evento, tanto para aproximar os alunos dos indígenas e quilombolas, quanto para divulgar as discussões étnicas das aulas com professores de outras escolas da região, e que estimularam o desejo da comunidade escolar em agir em prol das aldeias e quilombos de Paraty (RJ), transformando os $\operatorname{corpos}^{9}$ em fato social total ${ }^{10}$.

\section{Descrição e interpretação do material}

Para contextualizar as danças tradicionais na Educação Física enquanto as suas músicas são desenvolvidas nas Artes, linguagens obrigatórias nos currículos de acordo com a Lei no 13.278 (BRASIL, 2016), fez-se uma tempestade de ideias com os alunos dos terceiros (EM), momento que se conceituou o conteúdo; instigaram-se os objetivos do mesmo no currículo; compreendeu-se a relação do tema com outros conheci-

\footnotetext{
8. Reuniões entre professores e representantes de turmas para fechar conceitos e notas de um trimestre escolar.

9. Como tempo e espaço, por consequência produtor de sentidos e significados nos diferentes temas da cultura que perpassa o currículo escolar. Em uma relação social, a corporalidade seria, então, um termo da filosofia para designar a maneira pela qual o cérebro reconheceria e utilizaria o corpo como instrumento relacional com o mundo (DUARTE, 2019).

10. Maneiras de agir, de pensar e de sentir que exercem determinada força sobre os indivíduos, fazendo-os se adaptarem às regras da sociedade onde vivem, bem como elaborarem respostas para remodelar a sociedade (MAUSS, 2017).
} 
mentos presentes em outras disciplinas; sugeriram-se metodologias de trabalho; e discutiram-se as formas de avaliação. Nas aulas que se seguiram, aspectos históricos, políticos, econômicos, religiosos, filosóficos e sociais da região de origem das danças em questão foram apresentados, momento em que a cultura virou um território de conflitos pelo seu significado, tanto no interior do grupo, quanto no contato que estabeleceram com as comunidades (NUNES, 2016).

Importante refletir que, sem acompanhar a diversidade cultural do país, os alunos não têm acesso ao patrimônio de seus ancestrais, sendo natural que, para evitar um currículo inchado, transtornos com supervisores e/ou familiares dos jovens, alguns aspectos do patrimônio das comunidades populares sejam apagados. A legitimação dos conteúdos da Educação Física e de outras disciplinas deu-se para controle social e é baseada nos princípios da tradição, racionalidade e carisma (SCHLUCHTER, 1998), ou seja, tornou-se lei porque grande parte da população validou tais conteúdos sem tê-los construído democraticamente no século passado (BENEVIDES, 1990).

Neste momento histórico do CAp, existe condições de ultrapassar a validação dos discursos, aceitando que nem todos os conteúdos sofreram os dilemas de tais legalidades, mas que é necessário ensinar os alunos a ter ética e tolerância para abordar suas intencionalidades nos conteúdos. Considerando que a cidadania exige associação entre espaço participativo e educação política do cidadão (BENEVIDES, 1990), para se colocar neste tempo escolar, precisou-se ainda da noção de citacionalidade ${ }^{11}$ para que a dança tradicional saísse de seus locais de origem e chegasse à escola com significados originais e ampliação dos mesmos, a partir das mais variadas abordagens sobre o tema, pois as práticas corporais são artefatos da cultura que significam e são significadas, representam e são representadas, subjetivam e são subjetivadas, regulam e são reguladas em cada contexto escolar (PRÁTICAS..., 2018).

Durante as práticas de dança da região sudeste, colocaram-se roupas típicas e acessórios usados pelos indígenas ${ }^{12}$, quilombolas ${ }^{13} \mathrm{e}_{\text {caiçaras }}{ }^{14}$ de Paraty (RJ), respectivamente, no xondaro, no jongo e no caranguejo. Explicou-se que o xondaro é uma dança-luta-reza ${ }^{15}$, na qual os guerreiros resgatam movimentos de aves como o colibri (maino'i), gavião (taguato), andorinha (mbyju), sabiá (korosire) e papagaio (parakau ndaje) (TESTA, 2014) para treinar resistência corporal e espiritual em saltos, rastejos, esquivas, entre outras habilidades que imitam autodefesa, surpresa e reação imediata na selva (MONTARDO, 2002).

$\mathrm{Na}$ aldeia, os jovens apresentam-se com pinturas corporais, calça comprida e pés descalços, brincando, cantando e dançando em compasso ternário, em círculo e em sentido anti-horário para que todos tenham o mesmo poder de voz. Ao som instrumental invocatório ${ }^{16}$ às divindades, eles usam idiofone confeccionado com taquaras cortadas em tamanhos diversos (takuapu); violão com afinação e toques diferenciados da cultura brasileira (mbaraká); chocalhos globulares (mbaraká miri); membranofone feito com pele de cotia e usado por mensageiros guarani (angu'apu); flauta (mimby); clave (popygua); cordofone (ravé); e rabeca ou violino (mbarakapu, mbarakai) (MONTARDO, 2002). Nessa dança percebe-se o caminho de consumo das trocas na festa anual dos Mbyá ( $k u l a)$ que Martins (2005) nos apresentou quando falara da dádiva vivida pelas sociedades elementares e que permite prestações de sentimentos, volições e crenças, por um lado, e movimento corporal como demonstração de interações coletivas que antes não existiam, por outro.

\footnotetext{
11. Propriedade do signo de ser outra coisa na sua mesmice.

12. Os indígenas guarani vivem na Serra da Bocaina na aldeia Araponga em Paraty (RJ). A aldeia tem 40 pessoas que se organizam na Associação Comunitária Indígena de Araponga (ACIAR) desde 1990.

13. Os quilombolas do Campinho vivem na região da Costa Verde, no mesmo município. A comunidade tem 550 moradores que se organizam na Associação de Moradores do Quilombo do Campinho (AMOQC) desde 1999.

14. Os caiçaras de Ponta Negra ficam em uma ilha deserta. Ali vivem cerca de40 pessoas que se organizam em fóruns de comunidades tradicionais de Angra-Parati-Ubatuba, promovidos pela Coordenação Nacional das Comunidades Tradicional Caiçaras (CNCTC). 15. Segundo seu vice-cacique, a música cantada pelo coral durante a apresentação da dança permite a comunicação dos deuses que não falam, mas cantam para os xamãs (TESTA, 2014).

16. Desde o momento em que se aprende a tocar um instrumento, as faculdades de ajustamento de entonação e exatidão rítmica desaparecem, pois a circulação de saberes pelo corpo produz um próprio som. Para os Mbyá, o conhecimento refere-se à capacidade de saber e fazer/ saber e cuidar (erekokuaa) (PISSOLATO, 2007) de coisas, pessoas e lugares.
} 
O jongo do Campinho acompanha o jongo do Bracuhy, também da região de Paraty, há dez anos e é uma dança-canto-música ${ }^{17}$ que procura uma identidade própria para valorizar suas manifestações, já que parecia ter acabado na comunidade. O passo básico é feito de forma alternada, ora o pé direito vai a diagonal interna, ora o pé esquerdo realiza o mesmo movimento, finalizando a execução com um giro, permitindo vários deslocamentos em diferentes direções dentro de uma roda.

Advindo de Angola, esse jongo banto tem sido dançado de pés descalços, camisetas brancas, mulheres com saias florais e turbantes ${ }^{18}$ e homens com calça branca e kufi ${ }^{19}$, ao som de puítas (um ancestral da cuíca) e tambores de diferentes tamanhos e formatos (tambu ou caxambu - tambor maior; e o candongueiro tambor menor) (MAROUN, 2013). Nessa dança-canto-música, nota-se o caminho de consumo das trocas na festa anual dos remanescentes ( $k u l a$ ) que Martins (2005) nos apresentou quando falara da dádiva vivida pelas sociedades agonísticas e que permite prestações de sentimentos, volições e crenças, por um lado, e movimento corporal como demonstração de generosidades competitivas para retribuir cultura, por outro.

O caranguejo é uma ciranda caiçara ${ }^{20}$ que imita os movimentos da rede no mar. Os dançarinos resgatam tais movimentos para comemorar uma boa pesca de caranguejos ou para divertir visitantes da cidade que, quando dançam, viram membro da comunidade local. Em diferentes eventos, as pessoas usam roupas de passeio do dia a dia, brincam, cantam e dançam em compasso ternário, em duas fileiras festas dos pescadores -, ou em círculo com movimento anti-horário - festas turísticas de eventos de música, arte, literatura, gastronomia, religião e esporte náutico -, da região de Paraty.

Ao som de cantos e instrumentos como rabeca, violão, viola, timba, pandeiro, caixa de folia, dentre outros, eles dançam várias cirandas ${ }^{21}$ até o amanhecer. Nessa dança-música, percebe-se o caminho de consumo das trocas nas festas regionais ( $k u l a$ ) que Martins (2005) nos apresentou quando falara da dádiva vivida pelas sociedades modernas e que permite prestações de sentimentos, volições e crenças, por um lado, e movimento corporal como demonstração de competições de pessoas para serem retribuídas com presentes da festa/reconhecimento público/promessas de parcerias financeiras, por outro.

Ao dançar, também se discutiu a etnicidade na corporalidade enquanto fato social total, reconhecendo-se que a técnica é um caminho para se colocar no mundo, visto que todos são diferentes e que, por aceitação de pertencimentos ${ }^{22}$, as identidades são construídas, existindo diferentes possibilidades que se baseiam em outros aspectos listados anteriormente para se obter uma identidade étnica que será múltipla, jamais fixa.

Após as vivências, relatou-se a experiência com os diferentes grupos quando se esteve em contato com eles, dialogando sobre a dificuldade que eles têm de terem aulas na própria comunidade, de apresentarem sua cultura nas escolas do município, de estarem em eventos que lhes deem as mesmas oportunidades de voz e voto quando existe um debate sobre o patrimônio local. Finalizou-se a conversa com integrantes desses grupos relatando como eles dançam no cotidiano e como dançam nas festas com visitantes e descrevendo que as trocas de atenção, dinheiro ou comentários positivos sobre as culturas não geram uma equivalência entre os sujeitos, mas uma assimetria na qual cada um tem uma função e todas são consideradas importantes em um processo democrático.

A partir do reconhecimento do patrimônio material e imaterial que o PCT poderia explorar, pensou-se, com alunos e estagiários, na possibilidade de uma realização de troca de saberes e fazeres com os indígenas

\footnotetext{
17. Permite o canto dos ancestrais que segue um ritual de espiritualidade em aproximação com Nanã Buruquê - orixá mais velha da umbanda e do candomblé -, a partir do ritmo dos tambores.

18. Consiste em uma grande tira de tecido de até 45 metros de comprimento enrolada sobre a cabeça, de uso muito comum na Índia, no Bangladesh, no Paquistão, no Afeganistão, no Oriente Médio, no Norte da África, no Leste da África, no Sul da Ásia e em algumas regiões da Jamaica.

19. Um boné sem abas, curto e arredondado, usado por homens em muitas populações no Norte da África, Leste da África, África ocidental e Sul da Ásia.

20. A ciranda é um tipo de dança-música que fala do cotidiano, de um lugar meio monótono de se associar os movimentos das pessoas à origem da palavra zaranda, que é o movimento circular e devagar da farinha sendo peneirada. Já caiçara é o habitante tradicional do litoral das regiões Sudeste e Sul do Brasil, formados a partir da miscigenação entre índios, brancos e negros.

21. Arara, Chibacateretê, Caboclo veio, Cana-verde, Chapéu, Flor do mar, Limão, Marrafa e Tontinha.

22. Mais que pertencer a um grupo de negros, indígenas, homens, mulheres, crianças, idosos, gordos, magros etc., a identidade, segundo Pessoa (2017), dá-se na intersecção de diferentes pertencimentos/características que empoderam o sujeito.
} 
e quilombolas, dentro do CAp, em um primeiro momento, com a participação de outros professores da rede, bem como professores doutores da UFJF, para depois levar os alunos do colégio até as três comunidades que foram estudadas.

Nos meses que antecederam o evento, enquanto estudava outras regiões brasileiras, o grupo fez reuniões para averiguar como seria a avaliação da disciplina de EF caso optassem por uma mostra cultural durante o evento. Foi combinado que todos se esforçariam, mas se não fosse possível, após a entrega do relatório da proposta, ou seja, no primeiro dia útil após o término do evento, todos apresentariam suas danças tradicionais de forma contextualizada, com bebidas e comidas da região escolhida. Além disso, organizariam a "Troca de saberes e fazeres", envolvendo-se com os alunos e professores que colaborariam com a organização do evento ${ }^{23}$ e preocupando-se com a imagem institucional, com a alimentação, com o transporte que conduziria os convidados e com os responsáveis que acompanhariam e dormiriam com os indígenas e quilombolas, bem como com a arrumação do espaço necessário para o bom andamento do evento.

No evento, observou-se um movimento de reciprocidades entre os alunos que agiam de forma democrática (todos buscavam as soluções e, após amplo debate, tomavam decisões por votação; cada um se envolvia em uma atividade que lhe fosse familiar, mas quando um não conseguia resolver um problema, o outro o cobria trocando as funções momentaneamente; mesmo sem concordar, ninguém expunha o colega fora do espaço de construção das ideias), tocando, positivamente, os participantes da comunidade que foram à escola.

Alguns professores do PCT, por familiaridade com os temas "território e territorialidade", "meio ambiente" e "currículo escolar", contribuíram coordenando as discussões das mesas. Os estagiários assumiram diferentes frentes na estrutura do evento, apoiando os alunos formandos dos terceiros (EM) que, para além dessa frente, preferiram apresentar suas danças em outro momento, já que não estavam ensaiados e não tinham participação em massa ${ }^{24}$ dos pares. Os indígenas trouxeram seu coral para abrir o trabalho, enquanto os quilombolas seu jongo para fechá-lo. Paralelamente, sem organização pré-definida, houve iniciativa de um futebol entre indígenas e quilombolas que causou grande comoção, pois as regras eram mais cooperativas e o gol sofrido era comemorado da mesma forma que o gol feito. A comunidade participou das mesas, das apresentações culturais, como também adquiriu muitas peças de artesanato.

Essa culminância foi possível porque o Departamento de Educação Física e a direção do CAp prontificaram-se a fazer reuniões com gestores, encaminhar documentos e viabilizar a comunicação com a comunidade da cidade; a Pró-Reitoria de Extensão dispôs-se a orientar o processo de submissão do projeto de evento e a agilizar os trâmites entre diversos setores da UFJF, assumindo os gastos das viagens; a emenda parlamentar da deputada federal Margarida Salomão permitiu cobrir os gastos com cachês e alimentação para organizadores e grupos vulneráveis segundo Conselho de Comitê de Ética; e o Setor de Imagem Institucional cobriu o evento, bem como permitiu o acesso da comunidade aos saberes e fazeres que foram produzidos no CAp, mesmo após o término do evento.

Das experiências, ainda persistem algumas preocupações, sendo elas: os valores da escola atual proposta pelo ministro de educação, pois são embasados em uma política educacional desterritorializada, que tenta separar as práticas político-sociais de um local em prol de um projeto globalizado de cultura; os cursos de formação de professor, que permanecem precários em relação a direitos humanos, porque o sistema econômico vigente coloca o rendimento financeiro a frente da autonomia do trabalho e da vida social; e as exigências familiares, que ainda valorizam o jargão dos direitos individuais sem reconhecimento das especificidades dos direitos das diferentes comunidades, diante de uma sociedade que elenca valores desse grupo dominante e não de todos.

\footnotetext{
23. Para trazer um grupo caiçara, seria necessário aumentar o recurso financeiro que, atualmente, é de $R \$ 10.000,00$. Alunos e professores do CAp pensam que será mais interessante diversificar as comunidades e pleitear o recurso para o lugar que cederá o próximo Seminário de Institutos, Colégios e Escolas de Aplicação (SICEA).

24. Infelizmente, por problemas de comunicação da coordenação, alguns alunos entenderam que a atividade ocorreria em outro sábado. Com os professores já em deslocamento para buscar as comunidades, não houve oportunidade de confirmação de realização de trabalho.
} 
Para tanto, este trabalho pretende reterritorializar as práticas de dança por meio de novas condições de existência, em que observar a formação social de uma prática corporal; as relações que determinaram certos modos de ser, agir e pensar dos participantes; aspectos de dominação de um grupo sobre outro; as formas de regulação dos alunos sobre as outras culturas; e, os espaços de resistência e luta (NUNES, 2016), encaminha para os princípios da interculturalidade crítica (CANDAU, 2012). Nas aproximações, alunos desconstruíram preconceitos da vida diária dos indígenas e quilombolas, bem como de suas próprias; articularam as experiências dos grupos vulneráveis às suas para agir de outra forma na escola; resgataram os aprendizados do processo que poderiam ser úteis para professores da rede pública que enfrentam os mesmos problemas metodológicos dos professores do CAp; promoveram a formação básica, inicial e continuada da comunidade.

\section{Considerações finais}

Segundo o professor indígena Denilso, em uma conversa informal durante a organização da "I Troca de saberes e fazeres", "branco não aprende muito porque morre cedo, mais cedo do que tem consciência". Esse comentário fez com que todos pensassem nas diferentes realidades escolares antes de determinar os conhecimentos fundamentais para os alunos. Qual será a função da escola frente às novas demandas sociais? Que conteúdos deverão ser elencados para respeitar o patrimônio de cada sociedade? Como construir espaços e tempos que permitam autonomia crítica dos envolvidos? Se for sabido onde estão os saberes e fazeres, que se busque falar deles na escola, sem esquecer "de estar vivo" para ouvir a história dos que precisaram, em determinado momento, aprender os valores dos brancos para sobreviver, e que hoje, avisam os mesmos brancos de que estes precisam aprender valores elementares para continuar existindo enquanto sociedade.

Muitos jovens da rede pública não percebem a relação entre determinados conteúdos porque não são ensinados a observar saberes e fazeres cotidianamente, estimulando pouco uma capacidade de antecipação que é fundamental para agir com segurança em seu meio social. No período de convivência com indígenas e quilombolas, entendeu-se o quanto os conhecimentos são passados de forma prática, permanentemente repetitiva, até que a pessoa consiga realizar a tarefa sem crítica dos mais velhos.

Com a experiência, teve-se a noção de que acolhendo ideias, desejos, medos e curiosidades dos discentes, pode-se manter uma espiralidade de saberes e fazeres de diferentes realidades étnicas em prol da construção de conhecimentos nas diversas instituições de ensino da cidade de Juiz de Fora. Cabem aos professores, por meio da ação tripartida de dar, receber e retribuir saberes e fazeres, ressignificar as formas de escolhas de conteúdo a partir de valores de uma sociedade elementar e de uma agonística, com as quais tiveram oportunidades de dialogar, para mostrar ao Estado nacional que apenas uma educação democrática gera fortalecimento de todos os movimentos sociais, em uma nova perspectiva que valorize a crítica como algo que beneficiará a todos os cidadãos e não uma ameaça ao poder de seus representantes.

O bem comum, que foi a dança tradicional no caso da EF do CAp, nem sempre representou a identidade coletiva em detrimento da individual, mas quis evidenciar que a moral individual dos alunos advindos de diferentes bairros tinha que ser compatível com a sobrevivência desse coletivo democrático. Por meio da organização, execução e avaliação das aulas e do evento, da prova prática em uma mostra cultural com danças contextualizada, roupas, acessórios, penteados, maquiagens, comidas e bebidas, os corpos moldaram-se e ganharam sentido para dialogar com outros grupos escolares, para brincar, alimentar-se, rezar, ou seja, houve uma luta pela fixação de seus signos ou marcas identitárias na história da escola e uma sinalização de que cada turma de formandos necessitará de sua própria significação cultural.

Pensar uma educação de qualidade implica refletir sobre a superação da obrigação que a fundamenta nos tempos modernos: direito de retribuição exclusiva. O que se registrou em campo pode ser fonte de inspiração para um novo paradigma sobre o direito de produzir conhecimento. Evento como o que se realizou é difícil de ser concretizado, mas bastou interesse de um grupo para resolver todos os problemas que apareceram no percurso. Ao aproximar as comunidades dos alunos, entendeu-se que técnica tradicional de dança não serve para nada se não for compreendida como uma forma de execução a ser descoberta, 
experimentada, cuidada. Para agir de acordo com Mauss (2017), é necessário reconhecer a diferença entre as culturas corporais para respeitá-las, assim como reconhecer essa diferença no próprio corpo, sendo esse o lugar e o tempo do fato social total, capaz de exercer uma cidadania em diferentes espaços democráticos.

A escola pode ser um espaço de interrelação contínua entre indivíduos e sociedades, em que os modos de manifestação da cultura permitam reflexões mais humanitárias nas instituições modernas. Se esses momentos educacionais geraram cultura como maior bem comum - algo que não está nos livros -, nada mais democrático que desconstruir preconceitos de outros alunos sobre os patrimônios locais; articular conceitos de diversidade cultural, identidade étnica, corpo enquanto fato social, cidadania ativa, dentre outros, nas práticas político-pedagógicas da educação básica da região; resgatar os códigos identitários de cada grupo social que constitui este país em projetos coletivos nas escolas públicas; e promover experiências de interação entre professores e alunos em eventos que os aproximem, presencial ou virtualmente, as diferentes comunidades e que permitam o exercício da alteridade porque é um direito do cidadão e não porque é uma obrigação de retribuição social, conforme dissipado em muitos discursos governamentais.

\section{Referências}

ARRUTI, José Maurício. A emergência dos “remanescentes": notas para o diálogo entre indígenas e quilombolas. Mana, Rio de Janeiro, v. 3, n. 2, p. 7-38, out. 1997. Disponível em: https://www.scielo.br/scielo.php?script=sci_arttext\&pid $=$ S0104-93131997000200001. Acesso em: 11 maio 2020 .

BENEVIDES, Maria Victória. Cidadania Ativa, Democracia Semidireta: referendo, plebiscito e iniciativa popular. 1990. Tese (Livre-Docência) - Faculdade de Educação, Universidade de São Paulo, São Paulo, 1990.

BRASIL. Decreto $n^{\circ}$ 5.051, de 19 de abril de 2004. Promulga a convenção ${ }^{\circ} 169$ de organização internacional do trabalho - OIT sobre povos indígenas e tribais. Diário Oficial da União: seção 1, Brasília, DF, p. 1, 20 abr. 2004. Disponível em: http://www.planalto.gov.br/ccivil_03/_ato2004-2006/2004/decreto/d5051.htm\#textoimpressao. Acesso em: 8 maio 2020.

BRASIL. Decreto ${ }^{\circ}$ 6.040, de 7 de fevereiro de 2007. Institui a política nacional de desenvolvimento sustentável dos povos e comunidades tradicionais. Diário Oficial da União: seção 1, Brasília, DF, p. 316, 8 fev. 2007. Disponível em: http://www.planalto.gov.br/ccivil_03/_ato2007-2010/2007/decreto/d6040.htm. Acesso em: 8 maio 2020.

BRASIL. Lei no 13.278, de 2 de maio de 2016. Altera o $\$ 6$ do art. 26 da Lei no 9.394, de 20 de dezembro de 1996, que fixa as diretrizes e bases da educação nacional, referente ao ensino da arte. Diário Oficial da União: seção 1, Brasília, DF, p. 1, 3 maio 2016. Disponível em: http://www.planalto.gov.br/CCIVIL_03/_Ato2015-2018/2016/Lei/L13278.htm. Acesso em: 3 jul. 2020.

BRASIL. Lei ${ }^{\circ}$ 10.639, de 9 de janeiro de 2003. Altera a Lei ${ }^{\circ}$ 9.394, de 20 de dezembro de 1996, que estabelece as diretrizes e bases da educação nacional, para incluir no currículo oficial da Rede de Ensino a obrigatoriedade da temática "História e Cultura Afro-Brasileira”. Diário Oficial da União: seção 1, Brasília, DF, p. 1, 10 jan. 2003.

BRASIL. Lei $n^{\circ} 11.645$, de 10 de março de 2008. Altera a Lei no 9.394, de 20 de dezembro de 1996, modificada pela Lei $\mathrm{n}^{\circ}$ 10.639, de 9 de janeiro de 2003, que estabelece as diretrizes e bases da educação nacional, para incluir no currículo oficial da rede de ensino a obrigatoriedade da temática "História e Cultura Afro-Brasileira e Indígena". Diário Oficial da União: seção 1, Brasília, DF, p. 1, 11 mar. 2008.

BRASIL. Lei no 9.394, de 20 de dezembro de 1996. Estabelece as diretrizes e bases da educação nacional. Diário Oficial da União: seção 1, Brasília, DF, p. 27.833, 23 dez. 1996.

BRASIL. Resolução CNE/CEB no 8, de 20 de novembro de 2012. Define Diretrizes Curriculares Nacionais para a Educação Escolar Quilombola na Educação Básica. Diário Oficial da União: seção 1, Brasília, DF, p. 26, 21 nov. 2012.

CÂMARA DOS DEPUTADOS. Consultoria de Orçamentos e Fiscalização Financeira. Estudo Técnico n. ${ }^{\circ}$ 12/2016: impactos do "novo regime fiscal" - subsídios à análise da proposta de emenda à constituição - PEC nº 241/2016. Brasília, DF: Edições Câmara, 2016. Disponível em: https://www2.camara.leg.br/orcamento-da-uniao/estudos/2016/ EstudoTcnicon122016versao21ago_publicado.pdf. Acesso em: 6 maio 2020.

CANDAU, Vera Maria. Diferenças culturais, interculturalidade e educação em direitos humanos. Educação e Sociedade, Campinas, v. 33, n. 118, p. 235-250, jan./mar. 2012. Disponível em: https://www.scielo.br/pdf/es/v33n118/v33n118a15.pdf. Acesso em: 26 maio 2020. 
DUARTE, Cátia Pereira. Modos de ser quilombola, indígena e português: do cruzamento de pertencimentos corpóreos nas danças tradicionais às dádivas que consolidam as identidades da Colônia do Paiol, Aldeia Araponga e Comunidade de Areosa. 2019. Tese (Promoção à Classe de Professor Titular do Ensino Básico, Técnico e Tecnológico) - Colégio de Aplicação João XXIII, Universidade Federal de Juiz de Fora, Juiz de Fora, 2019.

FONSECA, Claudia. Quando cada caso não é um caso: pesquisa etnográfica e educação. Revista Brasileira de Educação, Rio de Janeiro, n. 10, p. 58-78, jan./abr. 1999.

GEERTZ, Clifford. A interpretação das culturas. Rio de Janeiro: Guanabara Koogan, 1989.

HALL, Stuart. Notes on deconstructing “the popular". In: STOREY, John (org.). Cultural Theory and popular culture. Athens: University of Georgia Press, 1998. p. 237-240.

MAROUN, Kalyla. Jongo e educação: a construção de uma identidade quilombola a partir de saberes étnico-culturais do corpo. 2013. Tese (Doutorado em Educação) - Departamento de Educação, Pontifícia Universidade Católica do Rio de Janeiro, Rio de Janeiro, 2013.

MARTINS, Paulo Henrique. A sociologia de Marcel Mauss: dádiva, simbolismo e associação. Revista Crítica de Ciências Sociais, Coimbra, n. 73, p. 45-66, 2005.

MAUSS, Marcel. Sociologia e Antropologia. São Paulo: Cosac Naify, 2003.

MAUSS, Marcel. Ensaio sobre a dádiva. Lisboa: Edições 70, 2017.

MONTARDO, Deise Lucy Oliveira. Através do Mbaraka: música e xamanismo guarani. 2002. Tese (Doutorado em Antropologia Social) - Faculdade de Filosofia, Letras e Ciências Humanas, Universidade de São Paulo, São Paulo, 2002.

PRÁTICAS corporais na Educação Física cultural - Marcos Neira. São Paulo: Grupo de Pesquisa em Educação Física Escolar, 2018. 1 vídeo (41 min 57 s). Publicado pelo canal Educação Física Cultural - GPEF-FEUSP. Disponível em: https://www.youtube.com/watch?v=BqLGHtFGfPc. Acesso em: 14 maio 2019.

NUNES, Mário Luiz Ferrari. Educação Física na área de códigos e linguagens. In: NEIRA, Marcos Garcia; NUNES, Mário Luiz Ferrari (org.). Educação Física Cultural: escritas sobre a prática. Curitiba: 2016. p. 51-72.

PESSOA, Jair de Morais. Saberes e culturas populares nas contradições da culturalização da sociedade. Revista de Educação Pública, Cuiabá, v. 26, n. 62/2, p. 493-508, maio/ago. 2017. Disponível em: http://periodicoscientificos.ufmt. br/ojs/index.php/educacaopublica/article/view/5495. Acesso em: 26 maio 2020

PISSOLATO, Elizabeth. A duração da pessoa: mobilidade, parentesco e xamanismo mbya (guarani). São Paulo: Editora UNESP: ISA; Rio de Janeiro: NuTI, 2007.

ROSSI, Amanda. Tudo o que você precisa saber sobre as usinas nucleares de Angra 1 e 2, e por que são diferentes de Tchernóbil. Folha de São Paulo, São Paulo, 23 jun. 2019. Disponível em: https://www1.folha.uol.com.br/ciencia/2019/06/ tudo-o-que-voce-precisa-saber-sobre-as-usinas-nucleares-de-angra-1-e-2-e-por-que-sao-diferentes-de-tchernobil. shtml. Acesso em: 22 maio 2020.

SCHLUCHTER, Wolfgang. Die Entstehung des modernen Rationalismus: eine Analyse von Max Webers Entwicklungsgeschichte des Okzidents. Frankfurt am Main: Suhrkamp, 1998.

SILVA, Tomaz Tadeu. A produção social da identidade e da diferença. In: SILVA, Tomaz Tadeu (org.). Identidade e diferença: a perspectiva dos estudos culturais. Petrópolis: Vozes, 2000. p. 73-102.

TESTA, Adriana Queiroz. Caminhos de saberes guarani Mbyá: modos de criar, crescer e comunicar. 2014. Tese (Doutorado em Antropologia Social) - Faculdade de Filosofia, Letras e Ciências Humanas, Universidade de São Paulo, São Paulo, 2014.

Data de submissão: 10/06/2020

Data de aceite: $22 / 10 / 2020$ 